\title{
Pregnancy complicated by previous cesarean section: a retrospective study
}

\author{
Poornima M.* \\ Department of Obstetrics and Gynecology, Saint George Hospital, Grant Government Medical College, Mumbai, \\ Maharashtra, India
}

Received: 04 September 2018

Accepted: 28 September 2018

*Correspondence:

Dr. Poornima M.,

E-mail: poornialiaas@gmail.com

Copyright: (c) the author(s), publisher and licensee Medip Academy. This is an open-access article distributed under the terms of the Creative Commons Attribution Non-Commercial License, which permits unrestricted non-commercial use, distribution, and reproduction in any medium, provided the original work is properly cited.

\begin{abstract}
Background: Previous Cesarean section (CS) is one of the important causes of CS in subsequent pregnancies. Moreover, repeated cesarean sections increase maternal as well as perinatal morbidity and mortality. We conducted this study to find out outcome of pregnancies in women who had a history of previous CS.

Methods: This was a retrospective study of patients of previous caesarean section for either maternal or fetal indications. The duration of study was 3 years. Total 215 patients were included in this study on the basis of a predefined inclusion and exclusion criteria. The indications, maternal and neonatal outcome were studied from medical records of the patients. Statistical analysis was done using SSPE 22.0 software.

Results: Out of 215 studied cases majority of the patients belonged to age group of 21-30 years (75.35\%) and were 2nd gravida (61.86\%). 164 (76.28\%) patients attended ANC OPD at least for 3 times during pregnancy. 73 (33.95\%) patients had $\mathrm{Hb}$ of less than 10 gms while blood transfusion was required to be given in $11(5.12 \%)$ patients. cesarean section was required in $172(80 \%)$ patients out of which $166(77.21 \%)$ patients had undergone emergency LSCS while in $6(2.79 \%)$ patients elective LSCS was done. Scar tenderness was the most common indication for repeat cesarean section. There was no maternal mortality in any patients while there was 1 still birth and 1 neonatal death.

Conclusions: Previous cesarean section is one of the important causes of CS in subsequent pregnancies hence decision of doing CS, especially primigravida, must be taken in accordance with strict guidelines and the practice of "cesarean section on demand" should be discouraged.
\end{abstract}

Keywords: Maternal and perinatal morbidity, Previous cesarean section, Outcome, Trial of labor

\section{INTRODUCTION}

One of the most common surgeries performed during obstetrics and gynecology practice is cesarean section (CS). ${ }^{1}$ If utilized properly CS has an immense value in decreasing maternal as well as neonatal morbidity and mortality. With advances in obstetrics care, anesthetic techniques and modern intensive care CS has become a very safe surgery. ${ }^{2} \mathrm{CS}$ has an immense value in instances where normal delivery predisposes mother or the fetus to an unacceptable high risk of mortality or morbidity as seen in large for gestational age fetuses, eclampsia or fetal distress and impending fetal demise. Due to its indisputable effects on reduction in neonatal as well as maternal morbidity and mortality its incidence is increasing exponentially throughout the world including developing countries including India. ${ }^{3}$ The chances of CS increase in young patients, elderly primigravida, grand multipara and women of higher socio- economic than their counterparts of lower socio economic status ${ }^{4}$. Another emerging indication of CS in modern obstetric practice includes "Cesarean section on demand" which is defined as a primary cesarean section performed at the mother's request in order to avoid a vaginal birth, without any recognized medical or obstetric indication for the procedure. ${ }^{5}$ The indications of CS have been evolving 
over time and they are expected to evolve further on the basis of further research and clinical trials while there is no dispute that CS should not be delayed in patients in whom genuine indication for doing so is present, it must be emphasized that CS has important implications for future pregnancies. ${ }^{6}$

One of the important consequences of cesarean section is increased chances of delivery by $\mathrm{CS}$ in subsequent pregnancies as compared to vaginal or even instrumental deliveries. $^{7}$ Previous CS then becomes one of the common indications of CS in subsequent pregnancies. Thus, CS should be done on the basis of evidence based indications especially in primigravida patients. ${ }^{8}$ Careful Management of pregnancies complicated by previous CS are important due to increased incidence of complications such as increased risk of uterine rupture, increased chances of repeat CS, chances of scar pregnancy, increased chances of morbidly adherent placenta and post-partum hemorrhage. ${ }^{9}$ The situation becomes more unpredictable when medical records of previous CS is not available. Because of these complications of CS it is prudent to strictly adhere to the guidelines to avoid unnecessary CS and indications such as "CS on demand" must be actively discouraged. ${ }^{10}$ The unacceptably high cesarean section rates seen in some parts of India (such as more than $50 \%$ in Telangana) and the difference in CS rates in private and public hospitals in India paint a grim picture of the situation and proves that much needs to be done in this regard. ${ }^{11,12}$ One of the important steps in this regard would be to disseminate the information about the fact that while in some cases CS is genuinely indicated it is associated with complications in subsequent pregnancies where normal vaginal delivery becomes less likely. ${ }^{13}$

The author has conducted this retrospective study to find out outcome of pregnancies in women who have undergone cesarean section either for obstetric or fetal indications.

\section{METHODS}

This was a retrospective study of pregnant women with gestational age more than 28 weeks and who had previously undergone cesarean section for any reason. A Detailed history of present pregnancy regarding date of last menstrual period, and past history was noted.

If the patient had been referred from some other hospital, then the reason for such referral was also noted down. Detailed past history, obstetric and menstrual history, family and personal history were noted down from medical records. Nutritional status, built, height and weight of the patients were noted in the proforma. Relevant systemic examination was also done.

Vital data like pulse and blood pressure were recorded. Per abdominal examination was also noted down with respect to the height of uterus, position, lie, presence or absence of contractions, presence of FHS and its rate were noted. The patients were divided into booked or unbooked cases depending upon whether they attended antenatal clinics properly. Findings of per vaginal examination were noted in all cases. Basic investigations $\mathrm{Hb} \%$, bleeding time, clotting time, blood grouping and Rh typing, HIV, VDRL and HbSAg were recorded. A trial of labor was given in cases with singleton pregnancy and cephalic presentation with $\mathrm{Hb} \geq 9 \mathrm{gm} \%$ and interpregnancy interval more than 18 months and adequate pelvis. If any of the complicating factors were present then an elective cesarean section was done depending upon institutional protocol. Mode of delivery was noted. Any maternal risk factors such as maternal diabetes, eclampsia or premature rupture of membranes etc were also noted. All deliveries were attended by a pediatrician and neonatal resuscitation, if needed, was also done by the attending pediatrician. If the baby didn't cry immediately and if was found to be limp then resuscitation was done according to the institutional protocol and the neonates were shifted to NICU. APGAR scores at 1 minute and 5 minutes were noted. Causes of perinatal and neonatal mortality were noted. Patients were discharged as per institutional protocol or on patients request if there were no contraindications to such a discharge. Maternal and perinatal outcome was studied. Statistical analysis was done using SSPE 22. P value less than 0.05 was taken as statistically significant.

\section{Inclusion criteria}

- All patients with history of previous cesarean section.

- Gestational age more than 28 weeks.

- Those who gave informed consent to be part of the study.

\section{Exclusion criteria}

- Ectopic pregnancies.

- Multiple pregnancies

- Those who refused informed consent to be part of the study.

- Gestational age less than 28 weeks.

- Those patients in whom neonatal outcome couldn't be determined because of any reason.

\section{RESULTS}

This was a retrospective study of pregnant women with previous lower segment uterine section complicating pregnancies. The case records of 3 years were analyzed for this purpose. A total of 215 patients were included in this study on the basis of available records.

The analysis of the age groups of the studied cases showed that the most common age group of the studied cases was $21-30$ years $(75.35 \%)$ followed by 31 years and above $(24.19 \%)$. Only $1(0.47 \%)$ patient belonged to age group of less than 20 years. 
Table 1: Age group of the studied cases.

\begin{tabular}{|lll|}
\hline Age groups & No. of Patients & Percentage \\
\hline$<20$ years & 1 & 0.47 \\
\hline 21-30 years & 162 & 75.35 \\
\hline 31 years or above & 52 & 24.19 \\
\hline Total & 215 & 100.00 \\
\hline Mean age \pm SD $=26.19 \pm 4.28$ years. \\
\hline
\end{tabular}

Mean age of the patients was found to be $26.19 \pm 4.28$ years. Amongst the studied cases majority of the patients $(61.86 \%)$ were second gravida while 76 patients $(35.35 \%)$ were either 3 rd or 4 th gravida. 6 patients $(2.79 \%)$ were $5^{\text {th }}$ gravida or more.

Table 2: Gravida of the studied cases.

\begin{tabular}{|lll|}
\hline Gravida & No. of cases & Percentage \\
\hline $2^{\text {nd }}$ & 133 & 61.86 \\
\hline $3^{\text {rd }}$ & 76 & 35.35 \\
\hline $5^{\text {th }}$ & 6 & 2.79 \\
\hline Total & 215 & 100.00 \\
\hline
\end{tabular}

The analysis of the case records to find out successful vaginal birth after cesarean section (VBAC) showed that out 215 studied cases there was a history of successful vaginal deliveries only in 11 cases $(5.12 \%)$.

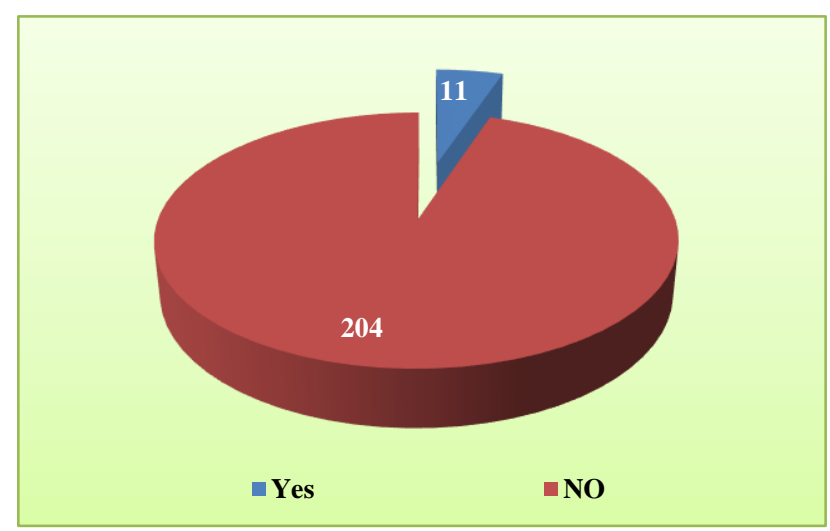

Figure 1: Prevalence of successful vaginal delivery after cesarean section.

The analysis of case records showed that majority of the studied cases were registered and 164 (76.28\%) have attended ANC OPD at least for 3 times during pregnancy whereas $51(23.72 \%)$ patients were unregistered.

Table 3: Registered versus unregistered cases in the study.

\begin{tabular}{|lll|}
\hline ANC visits & $\begin{array}{l}\text { No. of } \\
\text { cases }\end{array}$ & Percentage \\
$\begin{array}{l}\text { Registered (3 or more ANC } \\
\text { visits) }\end{array}$ & 164 & 76.28 \\
\hline $\begin{array}{l}\text { Unregistered (less than 3 ANC } \\
\text { visits) }\end{array}$ & 51 & 23.72 \\
\hline Total & 60 & 100 \\
\hline
\end{tabular}

The analysis of the case records showed that out of 215 cases time interval between past and present pregnancy was 2-4 years in $91(42.33 \%)$ cases followed by more than 4 years $(37.21 \%)$ and less than 2 years $(20.47 \%)$. Gestational age was between 37-39 weeks in majority of the patients $(54.42 \%)$. Amongst the studied women 73 $(33.95 \%)$ patients had $\mathrm{Hb}$ of less than $10 \mathrm{~g}$ while blood transfusion was required to be given in $11(5.12 \%)$ patients.

Table 4: Time interval between pregnancies, gestational age and hemoglobin status.

\begin{tabular}{|c|c|c|c|}
\hline Factors & & $\begin{array}{l}\text { No. of } \\
\text { patients }\end{array}$ & Percentage \\
\hline \multirow{3}{*}{$\begin{array}{l}\text { Time interval } \\
\text { between past } \\
\text { and present } \\
\text { pregnancy }\end{array}$} & $<2$ years & 44 & 20.47 \\
\hline & $2-4$ years & 91 & 42.33 \\
\hline & $\begin{array}{l}\text { More than } 4 \\
\text { years }\end{array}$ & 80 & 37.21 \\
\hline \multirow{3}{*}{$\begin{array}{l}\text { Gestational } \\
\text { age on } \\
\text { admission }\end{array}$} & $<37$ weeks & 33 & 15.35 \\
\hline & 37-39 weeks & 117 & 54.42 \\
\hline & > 39 weeks & 65 & 30.23 \\
\hline \multirow{3}{*}{$\begin{array}{l}\text { Hemoglobin } \\
\text { on admission }\end{array}$} & $7 \mathrm{~g}$ or less & 6 & 2.79 \\
\hline & $8-10 \mathrm{~g}$ & 67 & 31.16 \\
\hline & $>10 \mathrm{~g}$ & 142 & 66.05 \\
\hline \multirow{2}{*}{$\begin{array}{l}\text { Blood } \\
\text { transfusion } \\
\text { given }\end{array}$} & Yes & 11 & 5.12 \\
\hline & No & 204 & 94.88 \\
\hline
\end{tabular}

Out of 215 studied cases cesarean section was required in $172(80 \%)$ patients out of which $166(77.21 \%)$ patients had undergone emergency LSCS while in $6(2.79 \%)$ patients elective LSCS was done. Normal vaginal delivery was possible in $40(18.60 \%)$ patients while forceps and vacuum deliveries were done in $2(0.93 \%)$ and $1(0.47 \%)$ patients respectively.

\section{Table 5: Vaginal birth vs repeat LSCS after previous LSCS.}

\begin{tabular}{|c|c|c|c|}
\hline \multicolumn{2}{|c|}{ Maternal outcome } & $\begin{array}{l}\text { No. of } \\
\text { patients }\end{array}$ & Percentage \\
\hline \multirow{3}{*}{$\begin{array}{l}\text { Successful } \\
\text { vaginal birth } \\
\text { after cesarean } \\
\text { section }\end{array}$} & $\begin{array}{l}\text { Vaginal } \\
\text { delivery }\end{array}$ & 40 & 18.60 \\
\hline & Forceps & 2 & 0.93 \\
\hline & Vaccum & 1 & 0.47 \\
\hline \multirow{3}{*}{ Cesarean section } & Emergency & 166 & 77.21 \\
\hline & Elective & 6 & 2.79 \\
\hline & Total & 215 & 100 \\
\hline
\end{tabular}

The analysis of the indications for emergency LSCS showed that majority of emergency LSCS was done for scar tenderness $(37.67 \%)$. The other common indications for LSCS in patients with previous LSCS was found to be cephalopelvic disproportion $(9.30 \%)$, pregnancy induced hypertension $(3.26 \%)$ and breech presentation $(3.26 \%)$. Elective LSCS was done in $6(2.79 \%)$ patients. The indications for elective LSCS included cephalopelvic disproportion $(0.93 \%)$, big baby $(0.47 \%)$, bicornuate 
uterus $(0.47 \%)$, no live child $(0.47 \%)$ and patient not willing for vaginal delivery $(0.47 \%)$.

Table 6: Indications for emergency LSCS in studied cases.

\begin{tabular}{|lll|}
\hline Indications for Emergency LSCS & \\
\hline Scar tenderness & 81 & $37.67 \%$ \\
\hline CPD & 20 & $9.30 \%$ \\
\hline PIH & 7 & $3.26 \%$ \\
\hline Diabetes & 3 & $1.40 \%$ \\
\hline PIH+Diabetes & 2 & $0.93 \%$ \\
\hline Breech presentation & 7 & $3.26 \%$ \\
\hline Oligohydramios & 6 & $2.79 \%$ \\
\hline Post datism & 4 & $1.86 \%$ \\
\hline PROM & 4 & $1.86 \%$ \\
\hline Non-progression & 2 & $0.93 \%$ \\
\hline Fetal distress & 2 & $0.93 \%$ \\
\hline Not willing for VBAC & 8 & $3.72 \%$ \\
\hline Retinal detachment & 1 & $0.47 \%$ \\
\hline Seizure Disorder & 1 & $0.47 \%$ \\
\hline Failed Induction & 1 & $0.47 \%$ \\
\hline Cord Prolapse & 1 & $0.47 \%$ \\
\hline Short interconceptional period & 3 & $0.47 \%$ \\
\hline Placenta Previa & 3 & $0.47 \%$ \\
\hline Breech with PROM & 1 & $0.47 \%$ \\
\hline Abruptio placenta & 1 & $0.47 \%$ \\
\hline Obesity & 1 & $0.47 \%$ \\
\hline HBsAg Positive & 1 & $0.47 \%$ \\
\hline Post-datism with IUGR & 1 & $0.47 \%$ \\
\hline Severe Anemia & 1 & $0.47 \%$ \\
\hline Rh negative pregnancy & 1 & $0.47 \%$ \\
\hline Polyhydramnios & 1 & $0.47 \%$ \\
\hline Preterm labor & 2 & $0.93 \%$ \\
\hline Total & 166 & $77.21 \%$ \\
\hline
\end{tabular}

Most of the patients $(51.63 \%)$ were discharged from the hospital within 6 days from day of admission. 73 $(33.95 \%)$ patients remained admitted for 7-10 days. The duration of hospital stay was more than 11 days in 31 patients $(14.42 \%)$.

Table 7: Indications for elective LSCS in studied cases.

\begin{tabular}{|lll}
\hline Indications for Elective LSCS & & \\
Big Baby & 1 & $0.47 \%$ \\
\hline Cephalopelvic disproportion & 2 & $0.93 \%$ \\
\hline No live child & 1 & $0.47 \%$ \\
\hline Bicornuate uterus & 1 & $0.47 \%$ \\
\hline Patient Not Willing for VBAC & 1 & $0.47 \%$ \\
\hline Total & 6 & $2.79 \%$ \\
\hline
\end{tabular}

The study of birth weight of the neonates showed that $110(91.93 \%)$ babies had a birth weight between $2.5 \mathrm{~kg}$ to $3 \mathrm{~kg}$. birth weight of more than $3 \mathrm{~kg}, 2.0-2.5 \mathrm{~kg}$ and less than $2 \mathrm{~kg}$ was found in $65(30.23 \%), 36(16.74 \%)$ and 4 $(1.86 \%)$ patients respectively.

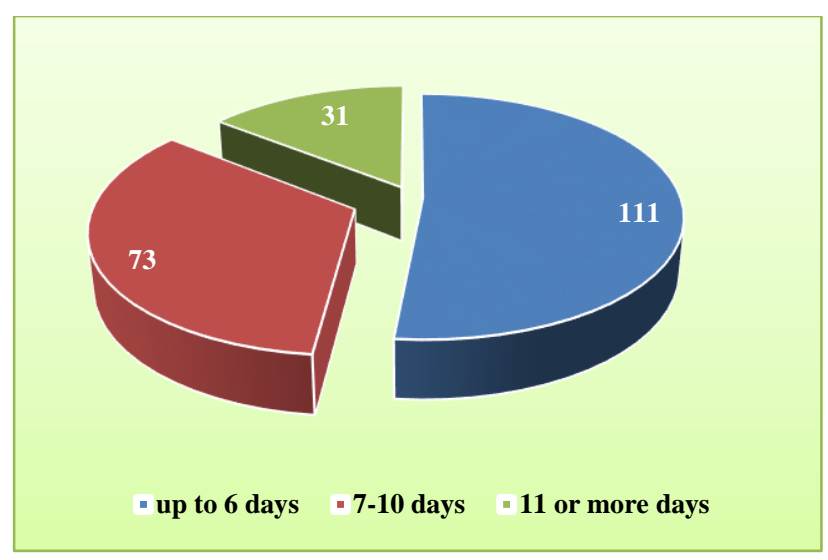

Figure 2: Duration of the hospital stay in patients.

Finally, the analysis of fetal outcome showed that out of 215 patients there was 1 stillbirth. Out of remaining 214 patients 1 neonate expired during neonatal period.

Table 8: Birth weight of the neonates.

\begin{tabular}{|lll|}
\hline Birth weight & Number of patients & Percentage \\
\hline$<2 \mathrm{~kg}$ & 4 & 1.86 \\
\hline $2-2.5 \mathrm{~kg}$ & 36 & 16.74 \\
\hline $2.6-3.0 \mathrm{~kg}$ & 110 & 51.16 \\
\hline$>3 \mathrm{~kg}$ & 65 & 30.23 \\
\hline Total & 215 & 100.00 \\
\hline
\end{tabular}

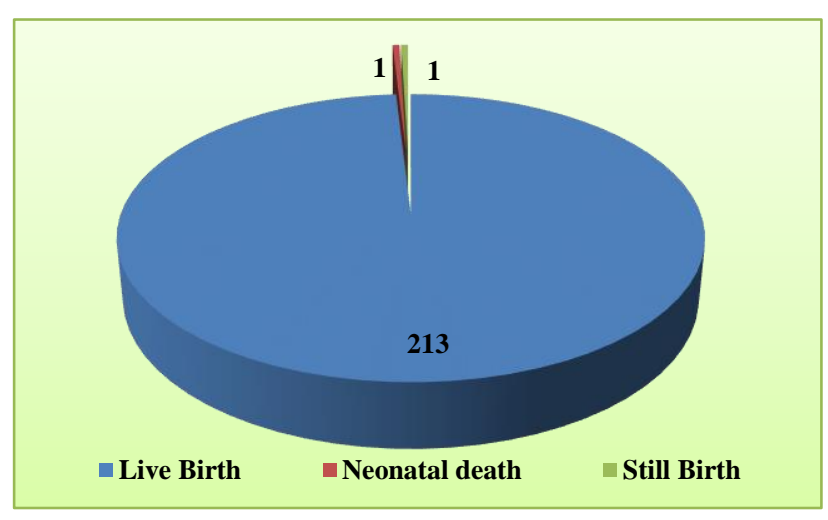

Figure 3: Fetal outcome in studied cases.

\section{DISCUSSION}

Proper management of pregnancies with history of previous cesarean section is an important aspect of obstetric practice. These patients have a higher rate of obstetric complications if trial of labor is given in these patients. ${ }^{14}$ With shrinking family size and increased education level less number of patients and treating obstetricians are likely to be willing for VBAC but in societies or cultures where a big family size is a norm VBAC becomes a necessity. Vaginal birth after cesarean (VBAC), though is possible in many cases, may be associated with severe maternal and perinatal complications. 
Moreover, it's not always possible to accurately predict which patient will have complications following trial of labor and every woman with previous cesarean section, irrespective of indication of previous cesarean, should be considered high risk and managed accordingly. ${ }^{15}$

The important question faced by obstetrician when faced with a pregnant patient who has had a previous cesarean section is whether to give a trial of labor or to go for elective cesarean section. When there are complicating factors such as eclampsia or cephalopelvic disproportion it becomes easy to decide in favor of cesarean section but in patients with no complicating factors a trial of labor may be given. ${ }^{16}$ Although trial of labor in these patients is relatively safe there are studies that suggest that trial of labor in these cases may be associated with increased maternal as well as perinatal morbidity. McMahon MJ et al performed a population-based, longitudinal study of 6138 women in Nova Scotia who had previously undergone cesarean section and had delivered a singleton live infant. ${ }^{17}$ Out of the studied cases 3249 women elected a trial of labor, and 2889 women chose to undergo a second cesarean section. The authors found that although the overall rate of maternal complications did not differ significantly between women who chose a trial of labor and the women who elected cesarean section major complications were nearly twice as likely among women undergoing a trial of labor as compared to those who opted for elective cesarean.

In present study the common indications for cesarean section in patients with h/o previous section were found to be scar tenderness (37.67\%) followed by cephalopelvic disproportion $(9.30 \%)$, pregnancy induced hypertension $(3.26 \%)$ and breech presentation $(3.26 \%)$. Switch et al in their study of $488(9.43 \%)$ patients with previous one caesarean delivery found that out of the studied cases 161 (33\%) underwent elective repeat caesarean and 327 (67\%) underwent trial of labor. Out of 327 patients 234 $(71.56 \%)$ had a successful TOLAC and 93 (28.44\%) had failed TOLAC. This is in contrast to present study in which $80 \%$ patient had undergone delivery by LSCS. Out of $80 \%$ majority of the LSCS in present study were emergency LSCS $(77.21 \%) .{ }^{18}$ Similar declining rates of vaginal births after cesarean deliveries are reported by National surveillance of USA which reported a troubling 63 percent decline in the rate of vaginal birth after cesarean delivery (VBAC) from 1996 (28.3\%) to 2003 $(10.6 \%)$. Similar rising trends in cesarean section rates have been reported by many authors globally. ${ }^{19}$

In present study the most common indication for repeat cesarean section was found to be scar tenderness (37.67\%) followed by cephalopelvic disproportion $(9.30 \%)$, pregnancy induced hypertension $(3.26 \%)$ and breech presentation (3.26\%). In a study by LydonRochelle MT the authors found that out of 493 women who underwent a repeat cesarean delivery without labor, "elective" (36\%) and "maternal request" (18\%) were the most common indications. Indications for maternal medical conditions $(3.0 \%)$ were uncommon. Among the 138 women with repeat cesarean delivery with labor, 60.1 percent had failure to progress, 24.6 percent a nonreassuring fetal heart rate, 8.0 percent cephalopelvic disproportion, and 7.2 percent maternal request during labor. ${ }^{20}$

\section{CONCLUSION}

The chances of cesarean delivery are more in women who had already undergone cesarean section for whatever indication. Multiple cesarean sections not only increase the maternal and perinatal morbidity and mortality but also increase the work load of already overloaded health system in developing countries. The culture of "cesarean section on demand" particularly in primigravida must be curbed by obstetrician to reduce the morbidity associated with multiple cesarean sections.

\section{Funding: No funding sources}

Conflict of interest: None declared

Ethical approval: The study was approved by the Institutional Ethics Committee

\section{REFERENCES}

1. National Collaborating Centre for Women's and Children's Health (UK). Caesarean Section. London: RCOG Press; 2011 Nov. (NICE Clinical Guidelines, No. 132.) Available at: https://www.ncbi.nlm.nih.gov/books/NBK115309/

2. Armson BA. Is planned cesarean childbirth a safe alternative?. Canadian Med Associat J. 2007;176(4):475-6.

3. Barber El, Lundsberg L, Belanger K, Pettker Cm, Funai Ef, Illuzzi Jl. Contributing Indications to the Rising Cesarean Delivery Rate. Obstet Gynecol. 2011;118(1):29-38.

4. Rahman M, Ahmad Shariff A, Shafie A, Saaid R, Md Tahir R. Determinants of Caesarean Risk Factor in Northern Region of Bangladesh: A Multivariate Analysis. Iranian J Public Health. 2014;43(1):16-27.

5. Morrison J, MacKenzie IZ. Cesarean section on demand. Semin Perinatol. 2003;27(1):20-33.

6. Hemminki E. Impact of caesarean section on future pregnancy--a review of cohort studies. Paediatr Perinat Epidemiol. 1996;10(4):366-79.

7. Biswas A. Management of previous cesarean section. Curr Opin Obstet Gynecol. 2003;15(2):123-9.

8. Mesleh RA, Asiri F, Al-Naim MF. Cesarean section in the primigravid. Saudi Med J. 2000;21(10):957-9

9. Mascarello KC, Horta BL, Silveira MF. Maternal complications and cesarean section without indication: systematic review and meta-analysis. Revista de Saúde Pública. 2017;51:105.

10. Duperron L. Should patients be entitled to cesarean section on demand?: YES. Canadian Family Physician. 2011;57(11):1246-8.

11. Singh P, Hashmi G, Swain PK. High prevalence of cesarean section births in private sector health 
facilities- analysis of district level household survey4 (DLHS-4) of India. BMC Public Health. 2018;18:613.

12. Neuman M, Alcock G, Azad K, Kuddus A, Osrin D, More NS, et al. Prevalence and determinants of caesarean section in private and public health facilities in underserved South Asian communities: cross-sectional analysis of data from Bangladesh, India and Nepal. BMJ Open. 2014;30;4(12):e005982.

13. Bangal VB, Giri PA, Shinde KK, Gavhane SP. Vaginal Birth after Cesarean Section. North Am J Med Sci. 2013;5(2):140-4.

14. Chua S, Arulkumaran S, Singh P, Ratnam SS. Trial of labour after previous caesarean section: obstetric outcome. Aust N Z J Obstet Gynaecol. 1989;29(1):12-7.

15. Mylonas I, Friese K. Indications for and Risks of Elective Cesarean Section. Deutsches Ärzteblatt Int. 2015;112(29-30):489-95.

16. Caughey AB, Shipp TD, Repke JT, Zelop C, Cohen A, Lieherman E. Trial of labor after cesarean delivery: the effect of previous vaginal delivery. Am J Obstet Gynecol. 1998;179(4):938-41.
17. McMahon MJ, Luther ER, Bowes WA Jr, Olshan AF. Comparison of a trial of labor with an elective second cesarean section. $N$ Engl J Med. 1996;335(10):689-95.

18. Siwach S, Lakra P, Sangwan V, Shivani, Kansal R, Mahendru R. To study the outcome of previous one caesarean pregnancies in a rural tertiary center of Haryana, India. Int J Reprod Contracept Obstet Gynecol. 2017;6(11):5008-12.

19. Betrán AP, Ye J, Moller AB, Zhang J, Gülmezoglu AM, Torloni MR. The Increasing Trend in Caesarean Section Rates: Global, Regional and National Estimates: 1990-2014. Zeeb H, ed. PLoS ONE. 2016;11(2):e0148343.

20. Lydon-Rochelle MT, Gardella C, Cárdenas V, Easterling TR. Repeat cesarean delivery: what indications are recorded in the medical chart? Birth. 2006;33(1):4-11.

Cite this article as: Poornima M. Pregnancy complicated by previous cesarean section: a retrospective study. Int J Reprod Contracept Obstet Gynecol 2018;7:4470-5. 